\title{
The Rhizobium leguminosarum biovar viciae nodO gene can enable a nodE mutant of Rhizobium leguminosarum biovar trifolii to nodulate vetch
}

\author{
A. Economou, ${ }^{1}+$ A. E. Davies, ${ }^{1}$ A. W. B. Johnston ${ }^{2}$ and J. A. Downie ${ }^{1}$ \\ Author for correspondence: J. A. Downie. Tel: +44 603 52571. Fax: +4460356844.
}

\footnotetext{
1 John Innes Institute, Colney Lane, Norwich NR4 7UH, UK

2 School of Biological Sciences, University of East Anglia, Norwich NR4 7TJ, UK
}

\begin{abstract}
Analysis of the nodulation characteristics of transposon-induced mutants of Rhizobium leguminosarum bv. viciae revealed that nodo and the closely-linked rhi genes contribute to nodulation of peas (Pisum sativum) and the vetch Vicia hirsuta. Although mutation of nodO alone had no significant effect on nodulation of either legume, a double mutant lacking both nodO and nodE nodulated both legumes very poorly. Similarly, a double mutant lacking nodE and either rhiA or rhiB nodulated peas less efficiently than a nodE mutant. Thus, although mutations affecting only the rhi genes normally have no observed effect on nodulation, these genes do appear to contribute to pea nodulation. When transferred to a wild-type strain of Rhizobium leguminosarum bv. trifolii, neither nodo nor the rhi gene region conferred pea or vetch nodulating ability. However, in a nodE mutant of $R$. I. bv. trifolii, nodo did confer a significant level of vetch nodulating ability, indicating that the secreted Nodo protein can play a role in determining legume recognition by R. I. bv. viciae.
\end{abstract}

Keywords: nodO, nodulation, Rbizobium leguminosarum, Vicia birsuta, Pisum sativum

\section{INTRODUCTION}

The rhizobial nodulation genes are the principal determinants of specificity in the recognition that occurs between rhizobia and their legume hosts. These genes are collectively known as nod or nol genes and the products of several of them are involved in the biosynthesis of lipooligosaccharide nodulation factors (Göttfert, 1993). These 'Nod' factors can induce complete or partial nodule organogrenesis when added to the roots of some legumes even in the absence of bacteria (Truchet et al., 1991; Spaink $t$ al., 1991) and purified lipo-oligosaccharide Nod factors can induce the formation of cytoskeletal changes to root cells similar to those structures that are made prior to the formation of mature infection threads (Van Brussel et al., 1992). However, the development of normal infection threads requires the physical presence of bacteria expressing nod genes and the rhizobia grow along the infection threads to reach the newly-dividing plant cells that are destined to become the legume root nodule. It appears that, in addition to expressing the appropriate nod genes, infecting bacteria require an acidic exopoly-

†Present address: Department of Biochemistry, Dartmouth Medical School, 7200 Vail Building, Room 425, Hanover, NH 03755, USA. saccharide, since mutants defective in its synthesis are unable to produce nodules containing rhizobia (see Leigh \& Coplin, 1992).

Not all of the nod or nol genes are essential for nodulation of legumes. Mutation of certain nod genes results in a loss of ability to nodulate specific legume species within the normal cross-inoculation group of one rhizobial strain. For example, nodV and nodW mutants of Bradyrbizobium japonicum lose the ability to nodulate siratro (Macroptilium atropurpureum) but not soybean (Göttfert $e t$ al., 1990). In other cases, mutation of nod genes can increase the range of legumes nodulated. Thus, a nodE mutant of Rbizobium leguminosarum bv. trifolii acquires the ability to nodulate peas (Djordjevic et al., 1985).

Some mutations within specific nod genes have no discernible effect on nodulation of any of the legumes tested. In some strains of $R$. l. bv. viciae, mutations in $\operatorname{nod} M, \operatorname{nod} N, \operatorname{nod} T$ or $\operatorname{nod} O$ had no effect on nodulation (Surin \& Downie, 1988, 1989; Surin et al., 1990; Economou et al., 1989). This may be due to gene duplication, as is the case for $\operatorname{nod} M$, which encodes a glucosamine synthase, while a functional homologue is encoded by the housekeeping $\mathrm{glm} S$ gene (Marie et al., 1992). 
Table 1. Bacterial strains and plasmids

\begin{tabular}{|c|c|c|}
\hline Strain & Relevant characteristics & Source \\
\hline$\Lambda 34$ & R. l. bv. viciae strain $8401 / \mathrm{pRL} 1 \mathrm{JI}$ & Downie et al. (1983) \\
\hline$\Lambda 42$ & Derivative of A34 carrying nodE68:: Tn 5 & Downie et al. (1985) \\
\hline A 67 & Derivative of A34 carrying nod $093:: \operatorname{Tn} 3$ lac $Z$ & This work \\
\hline A 69 & Derivative of A34 deleted for nodFELMNTO and rbiABCR & Downie \& Surin (1990) \\
\hline A78 & Derivative of $\mathrm{A} 34$ carrying rbiB6: $: \operatorname{Tn} 3$ lac $Z$ & This work \\
\hline A91 & $\begin{array}{l}\text { Derivative of } \mathrm{A} 34 \text { carrying nodE } 68:: \operatorname{Tn} 5 \text { and } \\
\text { nod } 093:: \operatorname{Tn} 3 \text { lac } Z\end{array}$ & This work \\
\hline A93 & Derivative of $A 34$ carrying nodE $68:: \operatorname{Tn} 5$ and rbiA5:: $\operatorname{Tn} 3 l a c Z$ & This work \\
\hline A95 & Derivative of A34 carrying nodE68::Tn 5 and rbiBri::Tn 3 lac $Z$ & This work \\
\hline A99 & Derivative of $\mathrm{A} 34$ carrying rhi.A5: : Tn 3 lac $Z$ & This work \\
\hline ANU843 & R. l. bv. trifolii & Djordjevic et al. (1985) \\
\hline ANU927 & Derivative of ANU 843 carrying nodE: $: \operatorname{Tn} 5$ & Djordjevic et al. (1985) \\
\hline \multicolumn{3}{|l|}{ Plasmids } \\
\hline pIJ1086 & $\operatorname{nodLMNTO}$ rhi.ABCR & Downie et al. (1983) \\
\hline pIJ1089 & nod $A B C I J F E L M N T O$ rhiABCR & Downie et al. (1983) \\
\hline pIJ1332 & Derivative of pIJ1085 carrying nodE68:: $\operatorname{Tn} 5$ & Downie et al. (1985) \\
\hline pIJ1641 & Derivative of pI J1089 carrying rbiB6: : Tn 3 lac $Z$ & Economou et al. (1989) \\
\hline plJ1642 & Derivative of $\mathrm{pIJ} 1089$ carrying rbi A5:: Tn 3 lac $Z$ & Economou et al. (1989) \\
\hline plJ1652 & Derivative of pI J1089 carrying nodO93:: Tn 3 lac $Z$ & Economou et al. (1989) \\
\hline plJ1685 & Derivative of pIJ1086 carrying nodO93:: Tn 3lacZ & Downie \& Surin (1990) \\
\hline pIJ1750 & Derivative of pIJ1086 carrying rbiA9: :Tn 5 lacZ & Cubo et al. (1992) \\
\hline pIJ1788 & nod $O$ cloned on pLAFR 1 & Economou et al. (1990) \\
\hline
\end{tabular}

It is also evident that some genes which encode very different products may function synergistically. This was first noted with the nodFE and nodO genes (Downie \& Surin, 1990); nodF and nodE encode proteins similar to the acyl carrier protein and condensing enzyme domains of the fatty acid synthase (Shearman et al., 1986; Bibb et cil., 1989 ), and nodE is necessary for the synthesis of hostspecific nodulation factors carrying the $C_{18: 4}$ acyl group (Spaink te al., 1991). In contrast, nodO encodes a secreted protein with the ability to form pores in membrares (Sutton et al., 1993). A deletion mutant of R. l. bv. viciae lacking the nodFELMNTO genes (see Fig. 1) could not nodulate vetch, but could be partially complemented for nodulation by either a plasmid carrying nodF and nodE or cosmids carrying about $30 \mathrm{~kb}$ DNA including either nod $\mathrm{O}$ or the nodLMNTO gene region. Mutation of nodO abolished the ability of the cosmids to complement the deletion mutant (Downie \& Surin, 1990). Thus, whereas mutation of nod $O$ normally had little or no effect on nodulation of vetch, in the absence of the nodFE region, nod $O$ was essential for the residual ( $\approx 50 \%$ of normal) nodulation seen with mutants lacking nodE. This result did not necessarily imply that nod $O$ was the only gene on the cloned $30 \mathrm{~kb}$ region that contributed to the residual nodulation. Indeed, in a subsequent study, Cubo et al. (1992) demonstrated that mutations in a gene cluster close to nodO could reduce the efficiency with which the cosmid clone could complement nodulation in the deletion mutant. This gene cluster contains the $r b i A, r b i B, r b i C$ and $r h i R$ genes (see Fig. 1), which appear to be found in R. l. bv. viciae strains but not other rhizobia (Dibb et cil.,
1984; Economou et al., 1989). These genes were called rhi since they were expressed in the rhizosphere and not within nodules (Dibb et al., 1984) and they are not under the same regulatory control as the nod genes (Economou et al., 1989; Cubo et al., 1992). Expression of the rbi.ABC genes depends on $r h i R$, which encodes a positively-acting transcriptional regulator with homology to known DNAbinding proteins (Cubo et al., 1992). Interestingly, Economou et al. (1989) found that a mutation in nodO (then called rolR) resulted in a marked decrease in the amount of the rhi $A$ gene product present in cells grown in the presence of hesperetin in order to induce nod gene expression. This indicated a possible link between NodO and the $r b i$ genes although no biochemical function for any of the $r b i A B C$ gene products has been established.

In this work, we have subcloned nodO and shown it to be an important determinant of host specificity. In addition, we have constructed a series of double mutants containing a derivative of the transposon $\operatorname{Tn} 3$ in nodO or the $\operatorname{rbi} A$ gene and the transposon $\operatorname{Tn} 5$ in the nodE gene and measured the combined effects of these mutations on nodulation.

\section{METHODS}

Microbiological methods. Rbizobium strains are described in Table 1 and plasmids in Fig. 1 and/or Table 1. Plasmids were transferred by conjugation from Eschericbia coli to the $R$. leguminosarum strains using the helper pRK2013 (Figurski \& Helinski, 1979) and selecting on TY (complete) medium (Beringer, 1974) containing streptomycin $\left(400 \mu \mathrm{g} \mathrm{ml}^{-1}\right)$ and 


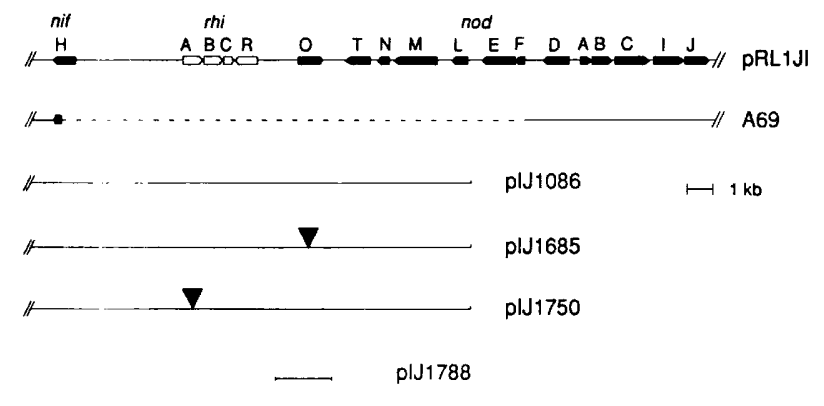

Fig. 1. Map of the nod-rhi gene region of R. I. bv. viciae. The locations, relative sizes and orientations of the nod (black arrows) and rhi (open arrows) genes on PRL1Jl are indicated. The broken line indicates the deletion in strain A69. plJ1086 and its derivatives plJ1685 and plJ1750, carrying the nod093::Tn3lacz and rhiA9::Tn5lacZ alleles (black triangles), respectively, are shown. The only $R$. I. bv. viciae gene on plJ1788 is nodO.

tetracycline $\left(5 \mu \mathrm{g} \mathrm{ml}^{-1}\right)$, or on $\mathrm{Y}$ (minimal) medium (Beringer, 1974) containing tetracycline $\left(2 \mu \mathrm{g} \mathrm{ml}^{-1}\right)$. Selection for Tn3HoHol (hereafter referred to as Tn3lacZ) on pIJ1685 in Rhizobium was on the same media containing $50 \mu \mathrm{g}$ carbenicillin $\mathrm{ml}^{-1} ; 10 \mu \mathrm{g}$ carbenicillin $\mathrm{ml}^{-1}$ was used to select for Tn3lac $Z$ alleles on PRL1 JI.

It was possible to construct double mutants since $r b i A, \operatorname{rbiB}$ and $n o d()$ mutations had previously been isolated using the transposon Tn3lacZ (Economou et al., 1989; Cubo et al., 1992) and a nod $L$ mutation had been isolated using $\operatorname{Tn} 5$ (Downie et al., 1985). Strains A67, A78 and A99 were made by transferring pI J1652, pl J1641 and pIJ1642 (Economou et al., 1989) into A34 and transferring the nodO93::Tn3lacZ, rbiB6::Tn3lacZ and rbiA5: 'I'n 3 lac $Z$ alleles, respectively, onto the symbiotic plasmid $\mathrm{PRL}$.1 JI by homologous recombination as described by Ruvkun \& Ausubel (1981), selecting for the Tn 3 lac $Z$ alleles using carbenicillin. Plasmid pI J1332, carrying the nodE68::Tn5 allele, was then introduced into strains A67, A78 and A99 and the nodl:68::Tn5 allele on pIJ1332 transferred onto the symbiotic plasmid pRL1 JI by homologous recombination, selecting for the Tn 5 allele with kanamycin. The recombinants were screened for sensitivity to tetracycline (to ensure loss of the vector) and shown to retain the Tn 3 lac $Z$ alleles by confirming that the expected levels of expression of $\beta$-galactosidase were retained. EcoRI-digested DNA from the double mutant strains A91, A93 and A95 was then confirmed to have the appropriate pattern of bands following hybridization with labelled pI J1089, which contains DNA spanning this region. This confirmed that no rearrangements had occurred within the nod - rbi gene region following recombination and that both transposons were in the appropriate locations.

Plant tests. Nodulation tests with the vetch Vicia birsuta were carried out on agar slopes as described by Knight et al. (1986), using a minimum of 20 plants per assay. Pea nodulation tests were done with Pisum sativum variety Wisconsin Perfection as described previously (Knight $e t$ al., 1986), using a minimum of 12 plants per assay. The results of tests on both species are expressed in Figs 2-5 as mean values with bars representing $\pm \mathrm{SE}$. In those cases where low levels of nodulation were observed, bacteria were isolated from six surface-sterilized nodules and reinoculated onto fresh plants. In each case this resulted in a similar delayed or low level of nodulation, indicating that reversion was not a significant problem. Measurements of acetylene reduction were made as described by Knight et al. (1986).

\section{RESULTS}

\section{Nodulation phenotypes of double mutants}

The nodulation efficiency of double mutants lacking nodE and nodO (strain A91) or nodE and rbiA (strain A93) or nodE and rbiB (strain A95) was compared with mutants carrying single mutations (Fig. 2). Mutation of nodO alone (strain A67) had no significant effect on nodulation of peas or vetch and mutation of nodE (strain A42) lowered the nodulation efficiency by about $30-40 \%$. However, the
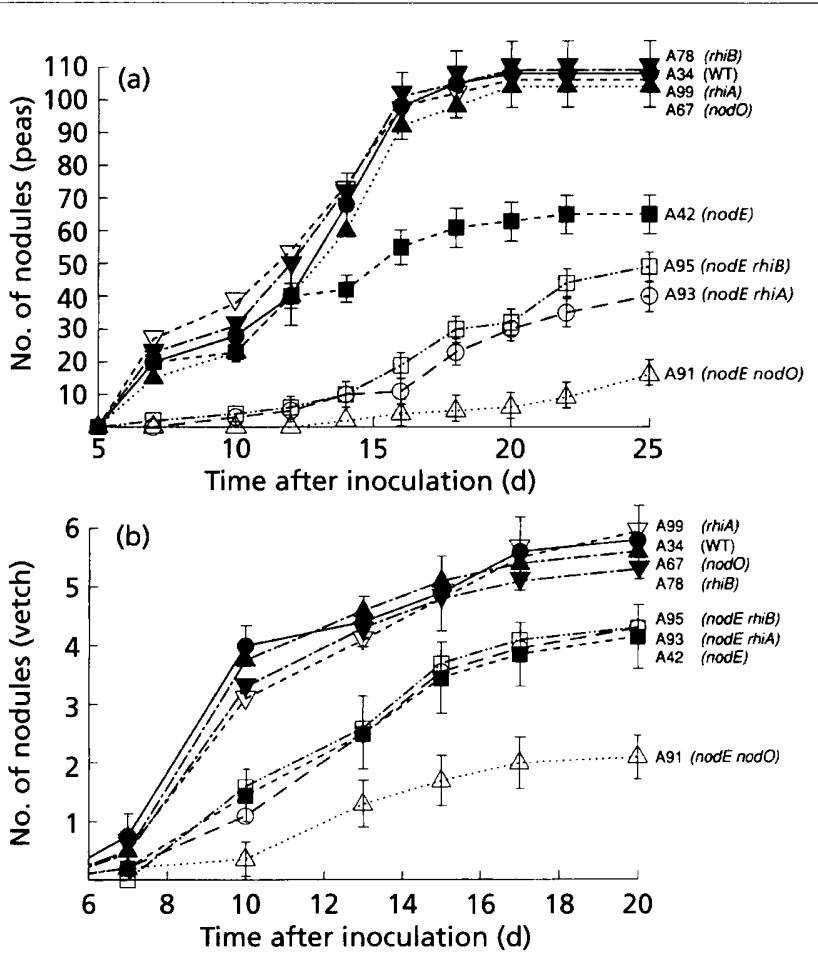

Fig. 2. Nodulation of peas and vetch ( $V$. hirsuta) by double mutants of $R$. $l$. bv. viciae. The mean numbers of nodules formed on peas (a) and vetch (b) by various strains of $R$. I. bv. viciae are shown:,$A 34 ; \mathbf{\square}, \mathrm{A42} ; \boldsymbol{\Delta}, \mathrm{A67} ; \boldsymbol{\nabla}, \mathrm{A78} ; \triangle, \mathrm{A91} ; \mathrm{O}, \mathrm{A93}$; $\square, A 95 ;$ and $\nabla, A 99$. For simplicity of presentation only selected (but typical) standard errors are shown. In (a) the standard errors shown correspond to those found with A34, A42, A95, A93 and A91; these values are similar to those found using the other strains, which indicate that there is no significant difference among A78, A34, A99 and A67 or between A95 and A93. In (b) the standard errors shown correspond to those found with $A 34, A 42$ and A91. Similar values were found with the other strains, indicating that the nodulation profiles of A34, A78, A99 and A67 are not significantly different from each other but are different from the others (particularly 10-18 d after incubation). Similarly A93, A95 and A42 do not differ significantly from each other but are different from A91 (particularly 18-25 d after incubation). The nodules formed were all pink and could reduce acetylene to ethylene, indicating that they contained nitrogen-fixing bacteroids. 
double mutant (A91) carrying transposons in both nodO and nodE poorly nodulated both peas (Fig. 2a) and vetch (Fig. 2b), indicating that nod $\mathrm{O}$ and nodE have additive effects on nodulation. It had been anticipated in the light of previous work (Downie \& Surin, 1990) that the double mutant might be unable to form nodules and the low residual level of nodulation seen here had not been expected.

The combination of the rbiA5:: $\operatorname{Tn} 3 l a c Z$ or the rbiB6:: Tn 3lacZ allele together with the nodE68:: $\operatorname{Tn} 5$ mutation (strains A93 and A95, respectively) also reduced the level of pea nodulation (Fig. 2a) compared with the effects of individual mutations in $r b i A$ or $r b i B$ (A78 and A99) or nodE (A42). The effect of the double mutation of rbi $A$ and nodE (A93) or $r b i B$ and nodE (A95) on nodulation was not as strong as that seen with mutation of both nod $O$ and nodE (A91). These effects are consistent with the rhi genes playing an ancillary role in pea nodulation as concluded previously (Cubo et al., 1992). On vetch, however, mutation of rbi A (A93) or rhiB (A95) in addition to mutation of nodE had no effect above that of mutation of nodE alone (A42) (Fig. 2b). In contrast, Cubo et al. (1992) noted that, in the absence of nodE, mutation of rbi genes did have an effect on nodulation of vetch. However, in those experiments the nodL gene product was also absent; this difference may account for the apparent discrepancy with the results seen here.

\section{nodO and rhi genes have additive effects on nodulation}

It has not been established whether the nodO gene alone can compensate for the nodulation defect of a strain lacking the nodFE gene region, or whether other genes (such as the $r b i$ genes) are necessary to allow nod $O$ complementation to be expressed (e.g. the rbi genes could be involved in an activation of NodO). This was addressed by transferring the subcloned nodO gene on $\mathrm{pIJ} 1788$ intto the deletion mutant A69 (carrying nod ABCDIJ but lacking nodFELMNTO and rhiABCR). The transconjugant induced a low level of nodulation on vetch, a property that A69 lacks (Downie \& Surin, 1990) (Fig. 3). The level of nodulation was similar to that seen with A.69 containing PI J1750, a derivative of $\mathrm{pI} 1086$ (nodLMNTO, rbi $A B C R$ ) carrying the rbi $A 9:: \operatorname{Tn} 5$ lac $Z$ allele. These observations indicate that, in the absence of the rbi gene region, nod $\mathrm{O}$ is less efficient at restoring nodulation to the deletion mutant A69. The nodules formed contained many bacteria as judged by light microscopy of fixed nodule sections (data not shown).

\section{nodO can confer vetch nodulating ability on a nodE mutant of $R$. I. bv. trifolii}

The observation that nod $O$ could allow strain A69 to nodulate vetch led us to investigate the possibility that nodO might confer some level of host specificity in nodulation. nod $\mathrm{O}$ on $\mathrm{pl} \mathrm{J} 1788$ was transferred into several strains of R. l. bv. trifolii and R. l. bv. phaseoli. In some cases the different R. l. bv. trifolii transconjugants induced

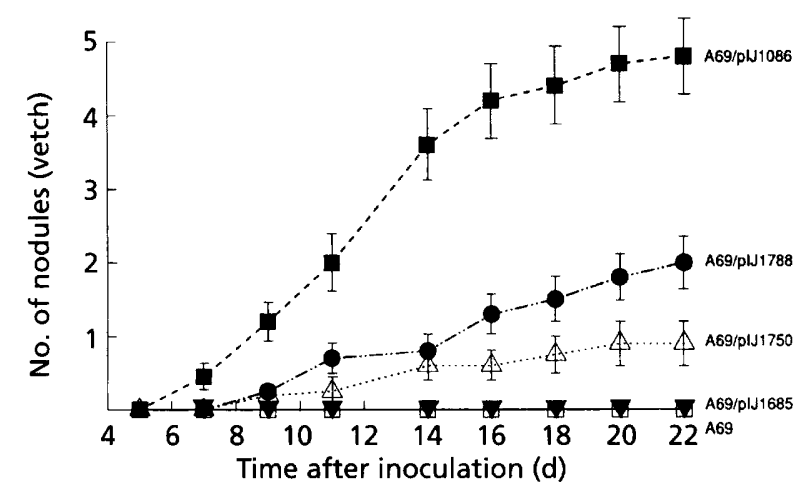

Fig. 3. Nodulation of vetch by $R$. I. bv. viciae strain A69 $(\boldsymbol{\nabla})$,

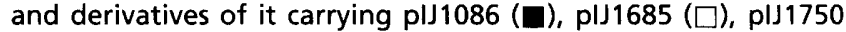
$(\triangle)$ or plJ1788 (O). plJ1685 is a derivative of plJ1086 carrying nodO93::Tn3lacZ; plJ1750 is a derivative of plJ1086 carrying rhiA9::Tn5lacZ; plJ1788 carries the cloned nodO gene.

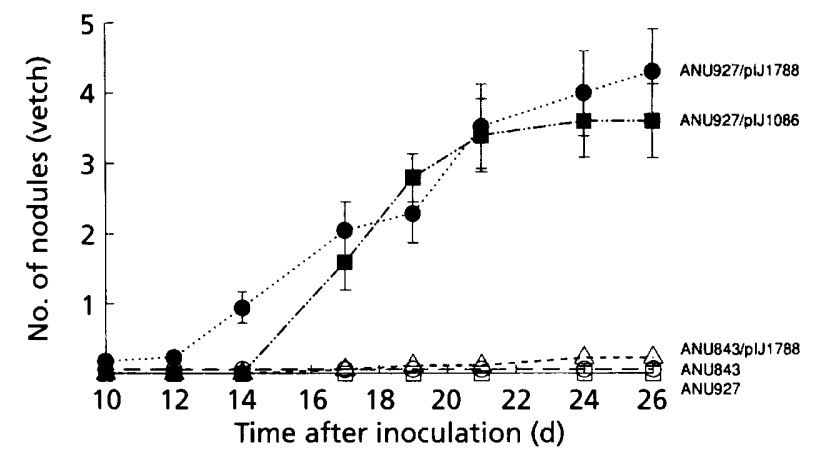

Fig. 4. Nodulation of vetch by R. I. bv. trifolii strains ANU843 (O), ANU843/pIJ1788 ( $\triangle)$, ANU927, either with or without

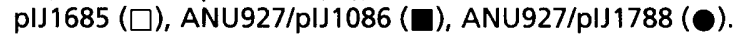

very low levels of nodulation on vetch but this was erratic. For example, when pIJ1788 was introduced into the well-characterized strain of R. l. bv. trifolii ANU843, only about $15 \%$ of the vetch plants inoculated formed one or two nodules after $21 \mathrm{~d}$ (Fig. 4). With the R. l. bv. phaseoli transconjugants, no nodulation of vetch was seen.

Djordjevic et al. (1985) reported that a nodE mutant of strain ANU843 could nodulate peas and we have confirmed this observation with its nodE mutant, ANU927 (Fig. 5). Surprisingly strain ANU927 did not nodulate vetch (Fig. 4). We were unable to detect a nodO homologue in strain ANU843 either by DNA hybridization or using NodO antiserum (Scheu et al., 1992). However, when nod $O$ on pI J1788 was transferred into strain ANL927, it acquired the ability to nodulate vetch (Fig. 4). A similar level of nodulation was seen with strain ANU927 containing plasmid pIJ1086. This clearly demonstrates an involvement of nod $O$ in the host-specific nodulation of vetch. The nodules formed on vetch by strain ANU927/pIJ1788 did contain large numbers of bacteroid 


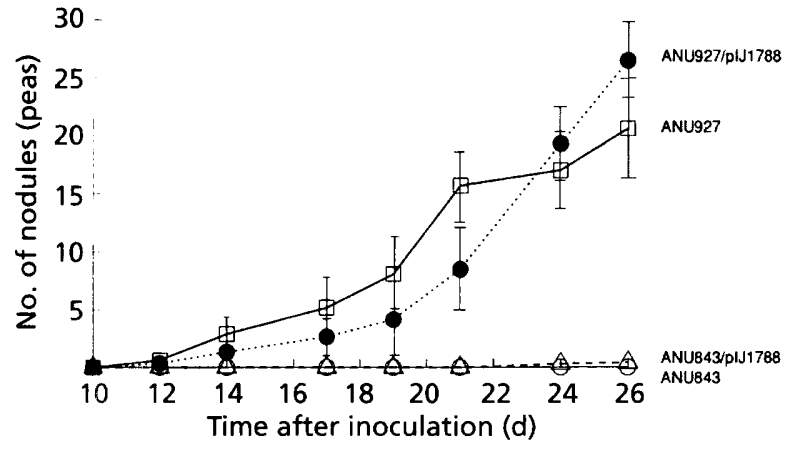

Fig. 5. Nodulation of pea by R. I. bv. trifolii strains ANU843 (O),

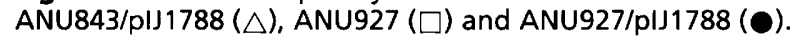

forms as judged by light microscopy of nodule sections (data not shown), indicating that nod $O$ stimulated the infection process. In parallel experiments with peas, plasmid pl J1788 did not increase the level of nodulation seen with strain ANU927 (Fig. 5).

To determine if the rbiABCR and the nodLMNT genes contribute any host specificity in nodulation, pI J1685 (the derivative of pIJ1086 carrying nodO93:: Tn3lacZ) was transferred into strain ANL927 and the transconjugants were tested for pea and vetch nodulation. There was no nodulation of vetch, indicating that the rbiABCR and nodLMNT genes present on pIJ1685 do not extend the host-range of nodulation in this system.

\section{DISCUSSION}

Whereas mutations in the R. l. bv. viciae nod $A$, nodB, nod $C$ and nodl) genes block nodulation, it is clearly difficult to uncover the relative contributions of some of the nod and other genes (such as rbi genes) to the overall efficiency of nodulation. One clear test is to transfer the appropriate genes into another biovar and check for extension or alteration of host range. This strategy previously revealed that the nodD and nodFE genes from $R$. l. bv. viciae determined specificity in R. l. bv. trifolii (Spaink et al., 1987, 1989; Surin \& Downie, 1989). In this work we have demonstrated that nodO can also act as a determinant of vetch nodulation specificity in a nodE mutant of $R$. $l$. bv. trifolii.

The nod $($ ) gene encodes a secreted protein (de Maagd $e t$ al., 1989; Lconomou et al., 1990) which binds $\mathrm{Ca}^{2+}$ (Economou et al., 1990). In contrast, several of the other nod gene products are involved in the synthesis of lipooligosaccharide Nod factors that are key determinants of specificity (Göttfert, 1993). In particular, the nodE gene product is involved in the formation of the novel $C_{\mathbf{1 8 . 4}}$ acyl group on the R. l. bv. viciae host-specific Nod factors and in the absence of nodE only $\mathrm{C}_{18: 1^{-c o n t a i n i n g}} \mathrm{Nod}$ factors are made (Spaink et al., 1991). The synergistic functions of NodO with the other nod gene products are unlikely to occur at the level of modification of the Nod factors, because these factors are identical if made in strains carrying or lacking nodO (Spaink et al., 1991). Instead, NodO may contribute to nodulation efficiency by forming ion channels in plant plasma membranes (Sutton et al., 1994). Interestingly, Ehrhardt et al. (1992) found that the Rhizobium meliloti lipo-oligosaccharide nodulation factor induced a depolarization of the plasma membrane of alfalfa root hair cells. Therefore NodO might increase or amplify the effect of the lipo-oligosaccharide Nod factor, but it is not clear how this could contribute to nodulation specificity. If the inappropriate Nod factors (or ratio of Nod factors) are made by the nodE mutant of R. l. bv. trifolii, perhaps only a very weak root hair depolarization is achieved and NodO can in some way amplify this effect. Alternatively, NodO might facilitate the uptake of Nod factors.

One way of looking at the contribution of the various genes involved in nodulation is to consider that nodulation tests may not necessarily be a good measure of the potential nodulation proficiency of a given rhizobial strain. By this we mean that if the nominal nodulation proficiency were reduced by, for example, $50 \%$, the number of nodules formed on a test legume might be normal because the plant can compensate for lower proficiency by allowing more infections to proceed to nodules. There are clear data that support the idea that the plant controls the final numbers of nodules formed (Caetano-Anolles \& Gresshoff, 1991) and that only a small proportion of infection events lead to nodule formation (Vasse et al., 1993). Thus, in the absence of some nod genes, no effect might be seen on nodulation efficiency. However, when the level of nodulation is substantially reduced (e.g. by the loss of nodE), bacterially-determined nodulation signals could become the limiting factor and the legume may no longer be able to compensate for the inefficiency in nodulation. Under these conditions it would then become possible to observe effects on nodulation of genes that otherwise appear to be unimportant. If this were the case, it could explain why the loss of nodO or $r b i$ gene expression only affects the level of nodulation of peas when nodE is also absent. Thus, it is possible that $\mathrm{NodO}$ may stimulate nodulation proficiency, in either the presence or absence of nodE, but this stimulation is actually only seen when the nodulation efficiency is very severely reduced, for example when only $C_{18: 1}$ acylated Nod factors are made as seen when nodE is absent (Spaink et al., 1991). It follows that there might be other, as yet unidentified, genes that could contribute to nodulation. However, the observations that nodO does not stimulate nodulation of peas by the nodE mutant of R. l. bv. trifolii and that the nodE $\operatorname{rbi} A$ double mutant nodulates vetch at the same efficiency as the nodE mutant, indicate that an incremental loss of nodulation efficiency is not the whole explanation. It is possible that other components such as activation of plant defences may also be important in the infection of legumes (Vasse et al., 1993). The precise mechanisms by which the nod $O$ and $r h i$ gene products stimulate nodulation have yet to be established but they appear to be rather different from any components yet identified in other rhizobial strains.

It seems that a key role for $\mathrm{NodO}$ may be to stimulate 
infection thread formation and this may be particularly important in mutants lacking nodE which make inappropriate lipo-oligosaccharide nodulation factors. If NodO does function by forming pores in the plasma membrane, its most likely site of action would be at the tip of the infection thread where the plant cell wall is being sunthesized and is much less likely to prevent the access of NodO to the plasma membrane. This offers the interesting possibility of an ion flux across the root-hair cell membranes in a localized region and this could be important for the cytoskeletal changes that are required for maintenance of infection thread growth.

\section{ACKNOWLEDGEMENTS}

M. A. Djordjevic kindly gave us R. l. bv. trifolii strains ANUB43 and ANU927. We thank E. Kannenberg for stimulating discussions, and D. A. Hopwood and N. J. Brewin for critical comments on the manuscript. This work was supported in part by a Sectorial Training Grant to A. E. from the EC, by an AFRC grant (PG208/554) to A.W. B. J. and J. A. D., and by a grant-inaid from the AFRC.

\section{REFERENCES}

Beringer, J. E. (1974). R factor transfer in Rbizobium leguminosarum. J Gen Microbiol 84, 188-198.

Bibb, M. J., Biro, S., Motamedi, H., Collins, J. F. \& Hutchinson, C. R. (1989). Analysis of the nucleotide sequence of the Streptomyces glaucescens tcm 1 genes provides information about the enzymology of polyketide antibiotic biosynthesis. EMBO J 8, 2727-2736.

Caetano-Anolles, G. \& Gresshoff, P. M. (1991). Plant genetic control of nodulation. Ann Rev Microbiol 45, 345-382.

Cubo, T., Economou, A., Murphy, G., Johnston, A. W. B. \& Downie, J. A. (1992). Molecular characterization and regulation of the rhizosphere-expressed genes rhi $A B C R$ that can influence nodulation by Rhizobium leguminosarum biovar viciae. J Bacteriol 174, 4026-4035.

Dibb, N. J., Downie, J. A. \& Brewin, N. J. (1984). Identification of a rhizosphere protein encoded by the symbiotic plasmid of Rhizobium leguminosarum. J Bacteriol 158, 621-627.

Djordjevic, M. A., Schofield, P. R. \& Rolfe, B. G. (1985). $\operatorname{Tn} 5$ mutagenesis of Rbizobium trifolii host-specific nodulation genes result in mutants with altered host-range ability. Mol \& Gen Cienet 200, 463-471.

Downie, J. A. \& Surin, B. P. (1990). Either of two nod gene loci can complement the nodulation defect of a nod deletion mutant of Rhizobium leguminosarum bv. viciae. Mol \& Gen Genet 222, 81-86.

Downie, J. A., Hombrecher, G., Ma, Q.-S., Knight, C. D., Wells, B. \& Johnston, A. W. B. (1983). Cloned nodulation genes of Rbizoirium leguminosarum determine host-range specificity. Mol \& Gen Genet 190 , 359-365.

Downie, J. A., Knight, C. D. \& Johnston, A. W. B. (1985). ldentification of genes and gene products involved in nodulation of peas by Rhizobium leguminosarum. Mol \& Gen Genet 198, 255-262.

Economou, A., Hawkins, F. K. L., Downie, J. A. \& Johnston, A. W. B. (1989). Transcription of rbiA, a gene on a Rbizobium leguminosarum bv. viciae Sym plasmid, requires $r b i \mathrm{R}$ and is repressed by flavonoids that induce nod genes. Mol Microbiol 3, 87-93.

Economou, A., Hamilton, W. D. O., Johnston, A. W. B. \& Downie, J. A. (1990). The Rbizobium nodulation gene nodO encodes a $\mathrm{Ca}^{2+}$ binding protein that is exported without $\mathrm{N}$-terminal cleavage and is homologous to haemolysin and related proteins. EMBO J 9, 349-354.

Ehrhardt, D. W., Atkinson, E. M. \& Long, S.R. (1992). Depolarization of alfalfa root hair membrane potential by Rhizobium meliloti Nod factors. Science 256, 998-1000.

Figurski, D. H. \& Helinski, D. R. (1979). Replication of an origincontaining derivative of plasmid RK2 dependent on a plasmid function provided in trans. Proc Natl Acad Sci US A 76, 1648-1652.

Göttfert, M. (1993). Regulation and function of rhizobial nodulation genes. FEMS Microbiol Rev 104, 39-64.

Göttfert, M., Grob, P. \& Hennecke, H. (1990). Proposed regulatory pathway encoded by the nodV and nodW genes determinants of host specificity in Bradyrbizobium japonicum. Proc Natl Acad Sci US.4 87, 2680-2684.

Knight, C. D., Rossen, L., Robertson, J. G., Wells, B. \& Downie, J. A. (1986). Nodulation inhibition by Rhizobium leguminosarum multicopy nod $A B C$ genes and analysis of early stages of plant infection. J Bacteriol 166, 552-558.

Leigh, J. A. \& Coplin, D. L. (1992). Exopolysaccharides in plantbacterial interactions. Ann Rev Microbiol 46, 307-346.

de Maagd, R. A., Wijfjes, H. M., Spaink, H. P., Ruiz-Sainz, J. E., Wijffelman, C. A., Okker, R. J. H. \& Lugtenberg, B. J. J. (1989). nodO, a new nod gene of the Rbizobium leguminosarum biovar viciae Sym plasmid encodes a secreted protein. J Bacteriol 171, 6764-6770.

Marie, C., Barny, M.-A. \& Downie, J. A. (1992). Rhizobium leguminosarum has two glucosamine synthases, GlmS and NodM, required for nodulation and development of nitrogen-fixing nodules. Mol Microbiol 6, 843-851.

Ruvkun, G. B. \& Ausubel, F. M. (1981). A general method for sitedirected mutagenesis in prokaryotes. Nature 289, 85-88.

Scheu, A. K., Economou, A., Hong, G.-F., Ghelani, S., Johnston, A.W. B. \& Downie, J.A. (1992). Secretion of the Rbizobium leguminosarum nodulation protein $\mathrm{NodO}$ by haemolysin-type systems. Mol Microbiol 6, 231-238.

Shearman, C. A., Rossen, L., Johnston, A. W. B. \& Downie, J. A. (1986). The Rhizabium gene nod $F$ encodes a protein similar to acyl carrier protein and is regulated by nodD plus a factor in pea root exudate. EMBO J 5, 647-652.

Spaink, H.P., Wijffelman, C. A., Pees, E., Okker, R. J. H. \& Lugtenberg, B. J. J. (1987). Rhizobium nodulation gene nodD is a determinant of host specificity. Nature 328, 337-339.

Spaink, H. P., Weinman, J., Djordjevic, M. A., Wijffelman, C. A., Okker, R. J. H. \& Lugtenberg, B. J. J. (1989). Genetic analysis and cellular localization of the Rbizobium host specificity-determining NodE protein. EMBO J 8, 2811-2818.

Spaink, H. P., Sheeley, D. M., Van Brussel, A. A. N., Glushka, J., York, W. S., Tak, T., Geiger, O., Kennedy, E. P., Reinhold, V. N. \& Lugtenberg, B. J. J. (1991). A novel, highly unsaturated, fatty acid moiety of lipo-oligosaccharide signals determines host specificity of Rhizobium leguminosarum. Nature 354, 125-130.

Surin, B. P. \& Downie, J.A. (1988). Characterization of the Rhizobium leguminosarum genes nod $L M N$ involved in efficient host specific nodulation. Mol Microbiol 2, 173-183.

Surin, B. P. \& Downie, J. A. (1989). Rhizobium leguminosarum genes required for expression and transfer of host specific nodulation. Plant Mol Biol 12, 19-29.

Surin, B. P., Watson, J. M., Hamilton, W. D. O., Economou, A. \& Downie, J. A. (1990). Molecular characterization of the nodulation gene nodT from two biovars of Rbizobium leguminosarum. Mol Microbiol 4, 245-252.

Sutton, J. M., Lea, E. J. A. \& Downie, J. A. (1993). The nodulation- 
signalling protein NodO from Rbizobium leguminosarum bv. viciae forms ion channels in membranes. Proc Natl Acad Sci USA (in press).

Truchet, G., Rochie, P., Lerouge, P., Vasse, J., Camut, S., de Billy, F., Prome, J.-C. \& Denarie, J. (1991). Sulphated lipo-oligosaccharide signals of Rinizobium meliloti elicit root nodule organogenesis in alfalfa. Nature 351, 670-673.

Van Brussel, A. A. N., Bakhuizen, R., Van Spronsen, P. C., Spaink, H. P., Tak, T., Lugtenberg, B. J. J. \& Kijne, J. W. (1992). Induction of pre-infection thread structures in the leguminous host plant by mitogenic lipo-oligosaccharides of Rhizobium. Science 257, 70-72.

Vasse, J., de Billy, F. \& Truchet, G. (1993). Abortion of infection during the Rbizobium meliloti-alfalfa symbiotic interaction is accompanied by a hypersensitive reaction. Plant J 4, 555--566.

Received 29 October 1993; revised 29 March 1994; accepted 11 May 1994. 